Notfall Rettungsmed 2009 · 12:415-418

DOI 10.1007/s10049-009-1229-7

๑) Springer Medizin Verlag 2009

\author{
F. Habibzadeh ${ }^{1}$ M. A. Winker ${ }^{2}$ \\ ${ }^{1}$ Shiraz NIOC Medical Education and Research Center, Shiraz \\ ${ }^{2}$ President, World Association of Medical Editors, Chicago
}

\title{
Duplicate publication and plagiarism: causes and cures
}

Duplicate publication and plagiarism are often referred to in a similar context, but their origins, issues, and remedies are substantially different. When an author intentionally or unintentionally republishes his or her own work without informing the editor of the previous publication, the result is duplicate publication. Duplicate publication is a form of redundant publication and refers to publication of an article in which the content overlaps substantially with one's paper already published in print or electronically [1]. Duplicate publication often violates copyright law and, in the case of multiply published studies, distorts results of meta-analyses, because if the duplication is not detected the results of the duplicate publications influence the meta-analyses results more than would a single publication $[2,3]$.

\section{(7) Duplicate publication often violates copyright law}

To try to prevent duplicate submission and publication - and recognizing that duplicate submission wastes peer review resources [4] - many journal editors ask authors at submission to declare that their work is original, not currently under consideration elsewhere, and also to submit any previously published, in press, or submitted articles with substantial overlaps with that work [5].

However, as unethical, misleading, and wasteful as duplicate publication is, it is generally considered less serious than plagiarism, fabrication, or falsification because the author is not claiming credit for someone else's work or fabricating information. It can, however, constitute a breach of the certification an author makes to a journal, which may have serious consequences for future consideration of the author's work at that and potentially other journals. It is important to distinguish between duplicate publication and secondary publication. Secondary publication, in which an author obtains permission from the original publisher to submit the work elsewhere, informs the editor at the new journal of the previous publication and, if accepted as a secondary publication, indicates in the article the existence of the previous publication; this is legitimate and acknowledged by the International Committee of Medical Journal Editors (ICMJE) [6]. Such secondary publication or simultaneous publication has been used to help reach more readers (as in the case of the ICMJE guidelines [6]) and more audiences in different languages.

In original research, duplicate text may occur in specific sections of the manuscript . These types of duplicate publication or "self-plagiarism" are defined by the World Association of Medical Editors (WAME) as "the practice of an author using portions of their previous writing on the same topic in another of their publications, without specifically citing it formally in quotes" [7]. The types of overlapping text have been described [8], but the limits of acceptable overlap- ping text have not been defined. It occurs most often in the Methods section and may be as required when multiple reports from a study overlap. On the other hand, duplicate Results text may signal salami publication, in which study results are reported in multiple overlapping papers, while overlapping Introduction and Discussion sections may suggest unoriginality of thought. Similarly, an experienced author may consider self-plagiarism in a review article acceptable when writing on the same topic multiple times, but the author should either place the replicated text in quotes or inform the editor that the author cannot write an original work on the topic.

Why does unacknowledged, unauthorized duplicate publication persist? Some authors may do it simply because they are not aware that it is wrong. They like to present their work in as many fora as possible to increase its visibility and to inflate their curriculum vitae for career promotion. Some authors who have already published their work in a local journal (mostly non-English) believe that re-publication of their work in an internationally recognized journal would cause no problem since the first journal is not indexed at all and thus the likelihood of double counting of their work is almost nil. However, considering the ubiquity of the Internet and taking into account that now even most local journals have their own Web sites, retrieving such gray materials during a good search is not unlikely. Authors should clearly disclose that the article 
was first published in another journal and language and if the author transferred copyright to that journal, obtain permission from the copyright holder.

On the other hand, plagiarism,"the use of others' published and unpublished ideas or words (or other intellectual property) without attribution or permission, and presenting them as new and original rather than derived from an existing source," is a form of scientific misconduct [7]. The word originates from the Latin word plagiarius meaning "kidnapper, seducer, and plunderer" and was first used in the sense of "literary theft" by the Roman poet, Martial, when complaining about a rival poet who read Martial's verses and passed them off as his own [9]. Although plagiarism is strongly condemned by the scientific community, it is unfortunately widespread throughout academia and is being increasingly detected; whether it is being increasingly committed cannot be determined for certain [10].

There are two important distinct types of plagiarism - "plagiarism of ideas" and "plagiarism of words." Both constitute scientific misconduct, but plagiarism of words is easier to detect and prove than plagiarism of ideas. The causes of plagiarism are many and varied, from frank stealing, to sloppy note-taking, to admiration for another's ability with a language. Many mainstream prestigious medical journals are published in English, and authors for whom English is a second language may be tempted to copy extensive passages from an Englishlanguage text within their own work. The challenge of communicating in a non-native language is understandable, considering the challenges of thinking in one language while conveying the message in another. Therefore, non-English speakers may commit plagiarism for lack of awareness and/or for want of linguistic expertise and editorial assistance [11]. Authors with English as a second language need more editing resources available - authors' editors or even a colleague with more facility with the language - to help them find their own voice in their non-native tongue. Journals should be willing to help edit for clarify work of authors for whom English is a second language, although language issues so dense as to obscure meaning must be addressed by the author with the help of a native speaker or author's editor. However, the lack of such resources for an author does not justify misconduct. If authors find particular passages they believe are appropriate for their work, they should place them in quotes, getting permission from the copyright holder if the passage is sufficiently long.

\section{$>$ There are two important distinct types of plagiarism - "plagiarism of ideas" and "plagiarism of words"}

Although the seriousness of plagiarism and duplicate publication differ, they are similar in terms of having at their core identical text, and therefore, the tools used for their detection are very similar. Freely available tools, accessible to authors, editors, reviewers, and readers, include Déjà vu and eTBLAST [12]. CrossCheck, a commercial product available through the digital object identifier (DOI) depositor CrossRef, has associated fees, but is more comprehensive in that it searches the full text of holdings of participating publishers as well as the free content available via the Internet. Such tools can be applied during manuscript review to permit detection of overlap before publication.

Regardless of the type of detection, the reader, and certainly the editor, must determine what degree of overlap is serious enough to bring to the attention to the author and the author's institution. No computer program can make those determinations and difficult decisions.

If duplicate publication is suspected by an editor, a range of actions may be taken depending on the seriousness of the situation and its circumstances [13]. The Committee on Publication Ethics (COPE) provides flowcharts for dealing with both duplicate publication and plagiarism [13]. The US Office of Research Integrity (ORI) investigates potential plagiarism if the work in question was funded by the United States government [14]. Generally speaking, the initial step is for the author to provide an explanation. Certainly, editors are more generous with junior authors whose improper behavior is more likely due to their lack of awareness than senior researchers who are expected to be aware of journal policies and abide by them. Journals that have authors warrant that the paper is not under review elsewhere and has not been previously published are better positioned to confront authors in cases of suspected duplicate publications. In the case of a few inadvertent overlapping sentences identified before publication, an editor may feel that author explanation, apology, and in most cases, rejection of the manuscript is sufficient. More substantial overlap, or a pattern of overlapping content, may warrant more serious interventions. If an article is determined by the editor to be a duplicate publication in whole (or substantially in part) after publication, the editor should notify the publisher of the original article of this determination and consider publishing a notice of duplicate publication along with an explanation from the author. If the duplicate publication concerns primary data, it is important that a notice of duplicate publication be made. The notice should become part of online databases as well as the article itself, so that it would be clear to a reader searching PubMed or another source that the article had already been published.

In the case of suspected plagiarism, the author should be asked for an explanation. If the editor is not satisfied with the explanation, he or she should generally formally notify the author's supervisor or author's institution sharing his/ her concern and the author's explanation. Cases of alleged plagiarism are often complex and require established processes to determine all the facts, and if it has occurred, to ascertain by whom. If a plagiarized article has been published as determined by an appropriate body with jurisdiction, a notice of retraction should be published along with a notice on the article itself on the journal's Web site, as well as online databases such as PubMed. The article should not be removed from its published location, since that would only confuse, not clarify, the status of the article. Unfortunately, the number of retracted publications recorded in PubMed has had an increasing trend in recent years [15]. Whether this increasing trend is due to an increased rate of the misconduct or use of more sensitive diagnostic tools that have become available inrecent years is a matter of debate [13]. 
What should editors, authors, and the research community do to prevent duplicate publication and plagiarism? Most important is educating investigators from students through senior faculty about how to prevent the practice and fostering a culture that does not accept such practices. Journals should have clear and accessible policies available to authors about duplicate publication and plagiarism and require them to warrant that the author meets criteria for authorship and assumes responsibility for the work, and that the work has not been submitted or published elsewhere. Editors should carefully seek out instances of duplicate publication and plagiarism and take appropriate careful but efficient action in reaching resolution and correcting the publishing record. Reviewers should consider the possibility of duplicate publication or plagiarism when they review and notify editors if they suspect either. Providing educational courses, preferably online and accessible for teaching authors, editors and reviewers; offering a place for whistleblowers to report suspected cases; and conducting research to identify different aspects of the issues are all important steps in defining and addressing the problems [16].

The current digitally interconnected world aids authors and researchers but facilitates duplicate publication and plagiarism. The same interconnected world aids in their detection. Editors, authors, and reviewers must be vigilant in identifying and preventing duplicate publication and plagiarism. Only through vigilance on all fronts can we protect the scientific literature we all are striving to improve to better scientific knowledge and ultimately patient care.

\section{Corresponding address \\ M. A. Winker MD}

President, World Association of Medical Editors 515 N State St., 60093 Chicago

IL/USA

margaret.winker@jama-archives.org

Acknowledgment. The authors would like to express their gratitude to Lorraine E. Ferris, PhD, LLM for her fruitful comments. Dr Ferris is Chair of the WAME Ethics Committee. Dr Winker is Deputy Editor, JAMA; the opinions expressed herein do not represent the views of JAMA or its editors.

\section{References}

1. Marusic A (2008) The role of the peer review process. In: Wells F, Farthing M (eds) Fraud and misconduct in biomedical research. Royal Society of Medicine Press, London, pp 135-160

2. Huston P, Moher D (1996) Redundancy, disaggregation, and the integrity of medical research. Lancet 347:1024-1026

3. Tramer MR, Reynolds DJ, Moore RA, McQuay HJ (1997) Impact of covert duplicate publication on meta-analysis: a case study. BMJ 315:635-640

4. Huth EJ (1986) Irresponsible authorship and wasteful publication. Ann Intern Med 104:257259.

5. WAME Publication Ethics Committee. Publication Ethics Policies for Medical Journals: Originality, Prior Publication, and Media Relations. Available from http://www.wame.org/resources/publication-ethics-policies-for-medical-journals\#orig (Accessed August 16, 2009)

6. International Committee of Medical Journal Editors (ICMJE). Uniform Requirements for Manuscripts Submitted to Biomedical Journals: Publishing and Editorial Issues Related to Publication in Biomedical Journals: Overlapping Publications. Available from http://www.icmje.org/publishing 4overlap.html. (Accessed August 25, 2009)

7. WAME Publication Ethics Committee. Publication Ethics Policies for Medical Journals: Plagiarism. Available from http://www.wame.org/resources/ publication-ethics-policies-for-medical-journals\#p lagiarism.(Accessed August 16, 2009)

8. von Elm E, Poglia G, Walder B, Tramer MR (2004) Different patterns of duplicate publication: an analysis of articles used in systematic reviews. JAMA 291:974-980 (Available from http://jama.amaassn.org/cgi/reprint/291/978/974.pdf)

9. Online Etymology Dictionary. Plagiarism. Available from http://www.etymonline.com/index. php?l=p\&p=19 (Accessed August 26, 2009)

10. Habibzadeh $F$ (2008) On stealing words and ideas. Hepatitis Monthly 8:171-172

11. Vessal K, Habibzadeh F (2007) Rules of the game of scientific writing: fair play and plagiarism. Lancet 369:641

12. Errami M, Sun Z, Long TC, George AC, Garner HR (2009) Deja vu: a database of highly similar citations in the scientific literature. Nucleic Acids Res 37:D921-924

13. Committee on Publication Ethics (COPE). Flowcharts. Available from http://publicationethics.org/ flowcharts (Accessed August 16, 2009)

14. Office of Research Integrity (ORI). ORI Policy on Plagiarism. Available from http://ori.dhhs.gov/policies/plagiarism.shtml (Accessed August 16, 2009)

15. Cokol M, Ozbay F, Rodriguez-Esteban R (2008) Retraction rates are on the rise. EMBO Rep 9:2

16. Smith R (2006) Research misconduct: the poisoning of the well. J R Soc Med 99:232-237

\section{Ausschreibung des Hanse- Preis 2009 für Intensiv- und Notfallmedizin}

Auch dieses Jahr schreibt die Fresenius-Stiftung wieder den mit 5000 Euro dotierten Hanse-Preis für Intensivmedizin aus. Mit dem Hanse-Preis werden jährlich hervorragende wissenschaftliche Publikationen in renommierten Zeitschriften gewürdigt.

Bewertet wird eine im Jahr 2009 publizierte Originalarbeit (Peer reviewed, experimentell oder klinisch, deutsch oder englisch) aus den Bereichen der Intensivoder Notfallmedizin. Das Wissenschaftliche Komitee wählt unter den Einsendungen acht Teilnehmer aus, die zum 20. Symposium Intensivmedizin und Intensivpflege (17. bis 19. Februar 2010) nach Bremen eingeladen werden

Einsendeschluss ist der 15. Dezember 2009. Bitte senden Sie Ihre Arbeiten per E-mail an folgende Adresse:

kontakt@hccm-consulting.de.

Nähere Auskünfte erteilt Frau Elke Stegmann. Alle Vortragswettbewerbe finden am Donnerstag, den 18.02.2010 statt. Die Preise werden im Rahmen des Get-togethers am selben Tag öffentlich verliehen. 
Hier steht eine Anzeige.

黛 Springer 